www.jmscr.igmpublication.org

Impact Factor 5.84

Index Copernicus Value: 71.58

ISSN (e)-2347-176x ISSN (p) 2455-0450

crossref DOI: _https://dx.doi.org/10.18535/jmscr/v5i12.80

Journal Of Medical Science And Clinical Research

\title{
A Prospective Observational Study of Ropivacaine and Ropivacaine with Dexamethasone, in Low Inter Scalene Brachial Plexus Blockade for Adult Upper Limb Orthopedic Surgeries in a Tertiary Care Centre
}

Authors

\author{
Dr Ganga G MD DA ${ }^{1}$, Dr Jasmine P Alex MD ${ }^{2}$ \\ ${ }^{1}$ Associate Professor, Govt. TD Medical College Alappuzha \\ ${ }^{2}$ Senior Resident, Govt. TD Medical College Alappuzha
}

\begin{abstract}
Background and Objectives: Variety of adjuvants has been used to prolong the duration of local anaesthetic action after regional and peripheral nerve blocks. We have conducted an observational study on effect of dexamethasone on the onset of analgesia, duration of analgesia and adverse effects in upper limb orthopaedic surgeries performed under low interscalene brachial plexus blockade with the help of peripheral nerve stimulator using ropivacaine as local anaesthetic.

Methods: After ethical committee approval and informed consent from patients we performed a prospective observational study on patients scheduled for upper limb orthopaedic surgeries under low interscalene brachial plexus blockade. This study was done among two groups of patients belonging to ASA 1 and 2 which were comparable with regard to age, sex and weight. They were allocated into two groups using computer generated randomization. group $R$ received $28 \mathrm{~mL}$ of $0.5 \%$ ropivacaine with $2 \mathrm{~mL}$ sterile water $(n=20)$ and group $R D$ received $28 \mathrm{ml}$ of $0.5 \%$ ropivacaine with $2 \mathrm{~mL}$ dexamethazone $(n=20)$. Computer software SPSS version-19 (SPSS Inc., Chicago, Illinois, USA) was used for statistical analysis. Student's t-test and Chi-square test were used and $P<0.05$ was considered as significant.

Results: The onset of sensory block in group $R$ was $14.1 \pm 0.968$ min and group $R D$ was $13.85 \pm 1.13$ min $(P=0.45>0.05)$ and the onset of motor block in group $R$ was $15.7 \pm 1.3$ min and in group $R D$ was 15.35 $\pm 0.99 \min (P=0.34)$. The mean duration of analgesia in group $R$ was $521.75 \pm 85.98$ min and in group $R D$ was $1015.75 \pm 34.57 \min (P=0001<0.01)$. Both groups showed stable hemodynamic conditions and no complications were observed in either of the groups.

Conclusion: Perineural administration of dexamethasone with ropivacaine significantly prolongs duration of analgesia in brachial plexus blockade and is remarkably safe and cost effective method of providing post operative analgesia.
\end{abstract}

Keywords: Dexamethasone, ropivacaine, interscalene brachial plexus blockade.

\section{Introduction}

Brachial plexus block is popular and widely employed peripheral nerve block technique for perioperative anaesthesia and analgesia for upper limb surgeries. Various approaches have been described such as supraclavicular, interscalene, infraclavicular and axillary.
In our practice, we almost always use a low interscalene block technique which provides both intraoperative anesthesia and postoperative analgesia, either as an adjunct to general anaesthesia or as the primary anaesthetic. It consists of inserting the needle more caudally than 
in the commonly described procedure performed at the level of the cricoid cartilage.

Ropivacaine is used frequently as local anaesthetic in brachial plexus block as it has long duration of action from 5 to 8 hours. Many investigators have tried mixing local anaesthetic with various adjuvants like epinephrine, opioids, clonidine, ketamine, and midazolam, in an attempt to prolong analgesia from nerve blocks, but the results are either inconclusive or associated with side effects ${ }^{(5)}$. However the glucocorticoid $^{(7)}$; dexamethasone have found to be effective in some of the clinical studies (1),(2),(4),(5),(8),(10), (12).

Steroids have powerful anti inflamma-atory as well as analgesic property. They suppress inflammation through inhibition of phospholipase A2. Steroids also induce a degree of vasoconstriction there by reducing the local anaesthetic absorption. According to an experimental study conducted by Johansson et al, local application of methyl-prednisolone has been found to block transmission in nociceptive Cfibres but not in myelinated A-beta fibres ${ }^{(15)}$. The effect was reversible, suggesting a direct membrane action of steroids ${ }^{(15)}$. Corticosteroid also suppress ectopic neuronal discharge ${ }^{(16)}$. Perineural injection of glucocorticoid along with local anaesthetics is reported to influence the onset and duration of sensory and motor block $^{(5)(13)(14)}$.

A more attractive theory suggests that dexamethasone increases the activity of inhibitory potassium channels on nociceptive C-fibres via glucocorticoid receptors, thus decreasing the activity of these neurons ${ }^{(7),(8)}$

The current observational study was designed to test the hypothesis that dexamethasone as an adjuvant to local anaethetic ropivacaine in low interscalene brachial plexus block shorten the onset of sensory block, enhances the duration of analgesia, quality of block as compared with Ropivacaine alone.

\section{Materials and Methods}

A sample size of 40 adult patients posted for elective orthopaedic upper limb surgeries who fulfilled the inclusion and exclusion criteria were allocated into two study groups of 20 each, using computer generated randomization. Group $\mathrm{R}$ received inj. $0.5 \%$ ropivacaine $(28 \mathrm{cc})$ with $2 \mathrm{cc}$ sterile water and group RD received inj. $0.5 \%$ ropivacaine with $8 \mathrm{mg}$ (2cc) dexamethasone.

\section{Inclusion Criteria}

- Those who gave consent to take part in this study.

- Age group 18 to 55yrs.

- Body weight more than 50kg.

- Either sex.

- Americal society of Anaesthesiologists (ASA) physical status 1 and 2.

\section{Exclusion Criteria}

- Those who refused regional anaesthesia.

- Infection at the site of injection.

- Pre-existing neuropathy involving the surgical limb.

- History of allergy to local anaesthetics.

- Systemic use of corticosteroids for $>/=2$ weeks within 6 months of surgery.

\section{Study Variables and Measurements}

Analgesia was assessed by Visual Analogue Scale which is marked from 0 to 10 . In this scale 0 corresponds to no pain and 10 corresponds to worst pain possible.

Onset of analgesia: Sensory block was assessed by pin prick with $24 \mathrm{G}$ hypodermic needle every 2 minutes. The time at which loss of pain to pin prick sensation over the desired dermatomes was taken as the onset of analgesia.

End point of analgesia: It is the time at which patient complained of pain of more than 5 in Visual Analogue Scale.

Duration of analgesia: It is the time period between the onset of analgesia to the end point of analgesia. 


\section{Study Procedure}

After getting clearance from institutional research and ethical committees, study subjects were selected based on inclusion and exclusion criteria. Detailed preanaesthetic check up was done. A written informed consent was obtained. Preoperatively all selected patients were explained about visual analogue scale. All patients were premedicated with $\mathrm{T}$. Alprazolam $0.25 \mathrm{mg}, \mathrm{T}$. Omeprazole $20 \mathrm{mg}$ and $\mathrm{T}$. Ondansetron $4 \mathrm{mg}$ on preoperative day at 10:00 $\mathrm{pm}$ and at 6 am on the day of surgery.

On day of surgery patient was shifted to the operation theatre and an intravenous line was established. Standard patient monitors such as ECG, pulse oximeter, non invasive blood pressure were attached. Sedation was given with Inj. Midazolam $0.02 \mathrm{mg} / \mathrm{kg}$ IV. The patient was placed in supine position with the head turned away from the side to be blocked. The arms were resting along the side of the body.

Under antiseptic precaution, $1.5 \mathrm{~mL}$ of local anaesthetic was infiltrated subcutan- eously in the interscalene groove 2 finger breadth above clavicle. A $5 \mathrm{~cm}$ long stimulating needle was inserted approximately 2 finger-breadths above the clavicle and advanced at an angle almost perpendicular to the skin plane.

The nerve stimulation technique descr- ibed by Winnie $^{(12)}$, was used with muscle contraction at a stimulating current of 0.2 to $0.5 \mathrm{~mA}$. The motor response in the following muscles depending upon the site of surgery yielded a high success rate. (pectoralis, deltoid, triceps, biceps and forearm muscles). Once appropriate twitches of the brachial plexus were elicited, in patients belonging to group $\mathrm{R} 28 \mathrm{~mL}$ of $0.5 \%$ ropivacaine with $2 \mathrm{ml}$ sterile water and in group $\mathrm{RD}, 28 \mathrm{~mL}$ of $0.5 \%$ ropivacaine with $8 \mathrm{mg}(2 \mathrm{~mL})$ ) dexamethasone were injected slowly with intermittent aspiration to rule out intravascular injection.

After injection of the intended volume of local anaesthetic mixture, patients were evaluated at 2 min intervals for the development of sensory and motor block. Sensory block was assessed by loss of sensation to pinprick over various dermatomes of upper limb. Motor block was assessed by failure to abduct the shoulder.

Assessment of time of onset of analgesia, duration of analgesia and adverse effects were also done. The efficacy of post operative analgesia was assessed using a visual analogue scale; this score graded ( 0 no pain; 10 worst pain possible). Break through pain of more than 5 was managed with Inj. Tramadol $50 \mathrm{mg}$ IV and the time was noted; which was recorded as end point of analgesia.

\section{Results}

Collected datas were compiled, entered and subjected to statistical analysis using SPSS VERSION 19. For all statistical evaluation, chi square test was used as nonparametric test. Student's t test was used as parametric test to compare mean values between two groups with probability value of $<0.05$ was considered significant.

The graphical representation, analysis and inference with respect to different study variables are as follows.

\begin{tabular}{|l|c|c|c|}
\hline & Group R $(\mathrm{n}=20)$ & Group RD $(\mathrm{n}=20)$ & \\
\hline Onset of sensory block (minutes) & Mean 14.10 & Mean 13.85 & P value 0.45 \\
& SD 0.968 & SD 1.137 & \\
\hline Onset of motor block (minutes) & Mean 15.7 & Mean 15.35 & P value0.34 \\
& SD 1.3 & SD 0.99 & \\
\hline Duration of sensory block (minutes) & Mean 521.75 & Mean 1015.75 & P value 0.0001 \\
& SD 85.98 & SD 34.575 & \\
\hline
\end{tabular}




\section{JMSCR Vol||05||Issue||12||Page 31765-31771||December}

Mean onset of sensory block (minutes)

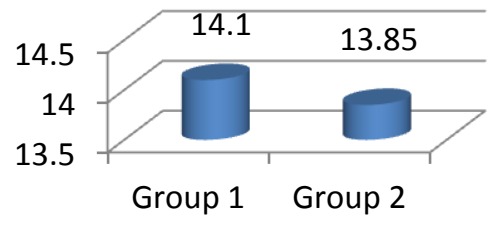

Mean onset of motor block (minutes)

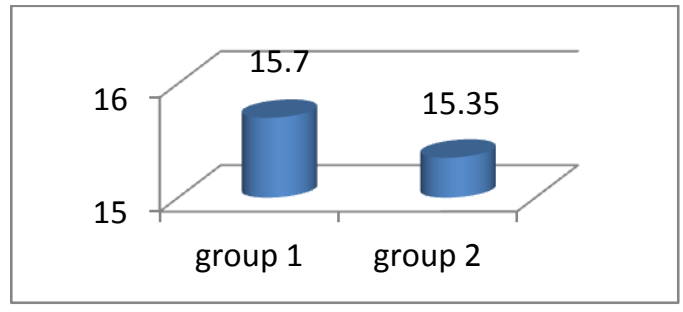

Mean duration of sensory block (minutes)

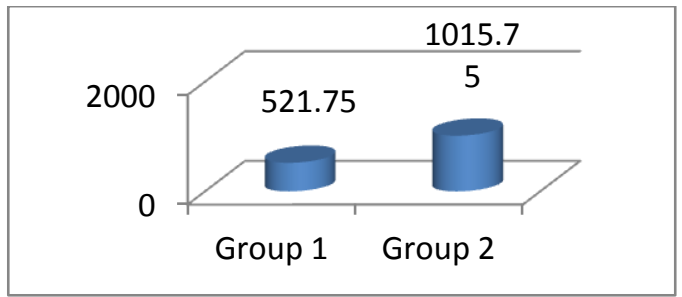

Comparison of heart rate (bpm)

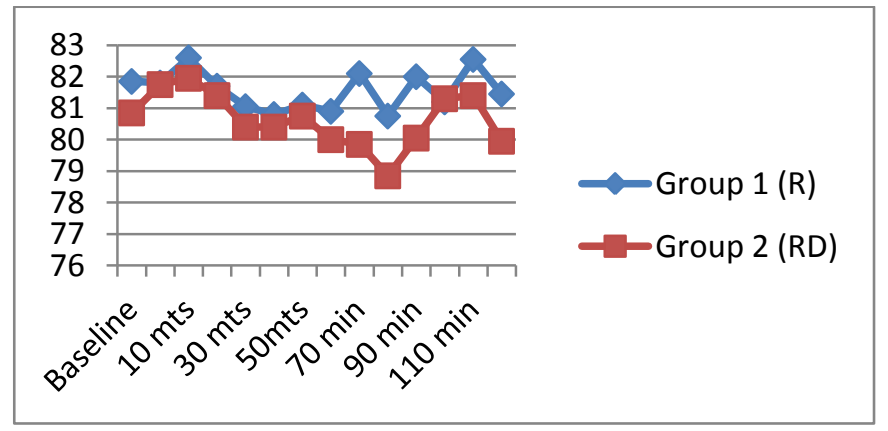

Comparison of SBP

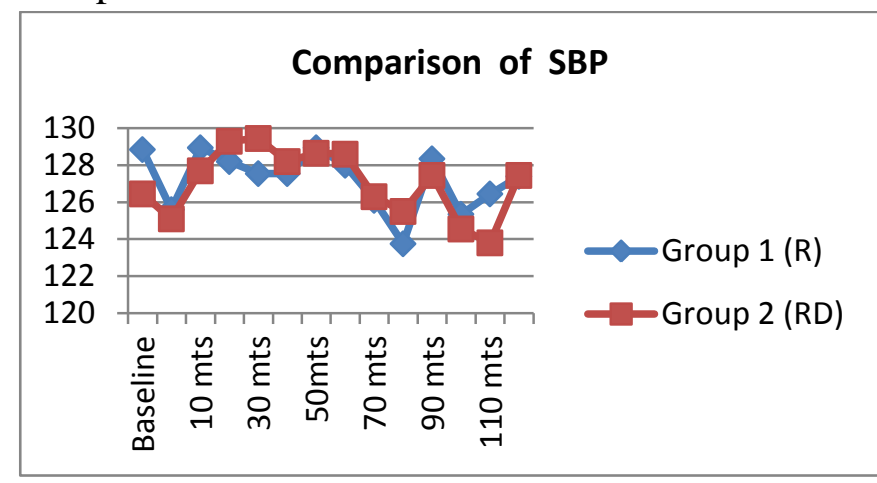

Comparison of $\mathrm{SpO} 2$

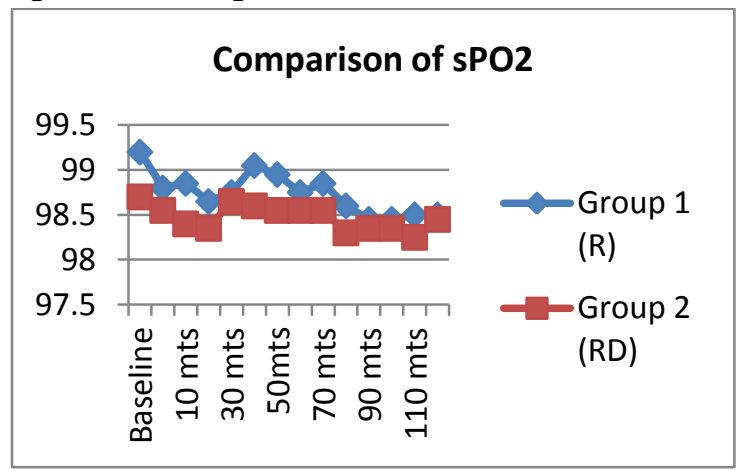

\section{Discussion}

Adequate pain relief during intraoperative and postoperative period is needed to decrease morbidity. The most important finding of the current investigation was the substantially longer duration of analgesia in patients receiving dexamethasone as adjunct to brachial plexus blocks compared to control. Specifically for the interscalene approach, the use of dexamethasone with ropivacaine prolonged analgesia duration for over 8 hours. In addition, the longer analgesic duration was accompanied by a lower consumption of postoperative opioids.

The brachial plexus block for upper limb surgery has proved to be a safer and effective method of regional anaesthesia. Variety of adjuvants have been used to prolong the duration of local anaesthetic action after regional nerve blocks. We have conducted a prospective observational study on effect of dexamethasone on the onset of analgesia, duration of analgesia and adverse effects in upper limb orthopaedic surgeries performed underlow interscalene brachial plexus blockade using ropivacaine as local anaesthetic. In our department, we currently use ropivacaine for peripheral nerve block because of its, easier reversibility after inadvertent intravascular injection, significant reduction in central nervous system and cardiovascular toxicity, lesser motor blockade, short onset-intermediate duration characteristics and greater differentiation of sensory and motor blockade.

Steroid adjuvants have been found to prolong the block duration when used in regional blocks. ${ }^{(5)}$ However, its mechanism of action is not clearly 
understood. Corticos- teroids may have a local effect on the nerve, ${ }^{(17)}$ or they may act by their anti-inflammatory effects ${ }^{(18)}$; they may alter the function of potassium channels in the excitable cells via glucocorticoid receptors ${ }^{(19)}$.

Only patients in the age group of 18-55 years belonging to ASA 1 and ASA 2 were included in the study. Onset and duration of sensory and hemodynamic stability were recorded at specified time intervals. Sensory block were assessed by pin prick method. The duration of analgesia is calculated as the time period between the onset of analgesia to the end point of analgesia.

Our study revealed that mean ages in group $\mathrm{R}$ and group RD were $44.85 \pm 8.248$ years and $40.45 \pm$ 8.003 years respectively. This difference in the ages between the two groups was statistically not significant ( $\mathrm{p}$ value $=0.09$ ). In our study there were 13 male patient and 7 female patient in group 1 and 11 male and 9 female patient in group 2. Our study revealed that there is no significant difference ( $p$ value $=0.51$ ) between group $R$ and group RD with respect to gender of the patients included in the study. Regarding the mean value of weight there were no statistical difference between two groups and were weight matched ( $p$ value $=0.15$ ).

There was no significant difference in onset of sensory block as well as in onset of motor block in group $\mathrm{R}$ and group RD. In our study mean duration of sensory block in group 1 is $1015.75 \pm$ 34.575 minute which was highly significant ( $p$ value $=0.001)$ as compared to group 2 , which is only $521.75 \pm 85.98$ minute.

The most interesting finding of our study was that dexamethasone was an excellent adjuvant with local anaesthetic ropivacaine for interscalene brachial plexus anaesthesia with no delay in onset time and with an advantage of prolonged postoperative pain relief. This finding was generally consistent with previous studies (1)(17). We observed around 2.0-fold prolongation of analgesia in group RD in comparison to ropivacaine group almost similar to Cummings et al. (1) who observed a 1.9-fold increase in the duration of ISB when dexamethasone was mixed with local anaesthetic. We observed that mean VAS score and rescue analgesic consumption was significantly less when dexamethasone was mixed with ropivacaine.

Since we performed a low interscalene approach which is more caudally than in the commonly described procedure performed at the level of the cricoid cartilage, it has been observed that diaphragmatic paresis which is an inevitable consequence of ISB was absent. Use of peripheral nerve stimulator helped to reduce total volume of drug injected. We used only $30 \mathrm{~mL}$ instead of large volumes reported in earlier reports.

There were no reported cases of complications like haemodynamic instability, Horners syndrome, hoarseness of voice, respiratory distress secondary to diaphraghmatic paresis. A potential advantage of perineural dexamethasone is the avoidance of undesirable side effects associated with the use of systemic dexamethasone ${ }^{(20)}$.

\section{Conclusion}

In conclusion, this study demonstrates that dexamethasone significantly prolongs the duration of analgesia resulting from a single-shot low ISB with ropivacaine $0.5 \%$ for upper limb orthopaedic surgeries. Dexamethasone also improved the quality of pain relief. Thou-gh it does not affect onset of sensory as well as motor block. Both groups showed stable hemodynamic conditions and no complications were observed in either of the groups. In addition, the longer analgesic duration was accompanied by a lower consumption of post-operative opioids. Thus it can be concluded that dexamethasone is a good adjuvant in interscalene brachial plexus block.

\section{References}

1. Cummings KC, Napierkowski DE, ParraSanchez I, Kurz A, Dalton JE et al. Effect of dexamethasone on the duration of interscalene nerve blockswith ropivacaine or bupivacaine. Br J Anaesth. 14 June 2011; vol. 107: 446-53 . 
2. Biradar PA, Kaimar P, Gopalakrishna K. Effect of dexamethasone added to lidocaine in supraclavicular brachial plexus block: A prospective, randomised, double-blind study. Indian $\mathrm{J}$ Anaesth . Mar-Apr 2013; vol. 57 (2): 180-4.

3. Interscalene Brachial Plexus block-The New York School of Regional Anaesthesia by admin 26 Sept 2013. http://www.nysora.com/techniques/nervestimulator-and-surface-based-ratechniques/upper-extremitya/3346interscalene-brachial-plexus-block.html.

4. Choi S, Rodseth R and McCartne CJL. Effects of Dexamethasone as a local anaesthetic adjuvant for brachial plexus block: a systematic review and metaanalysis of randomized trials. British Journal of Anaesthesia. 10 January 2014; vol. 112 (3): 427-39.

5. Golwala MP, Swadia VN, Dhimar AA, Sridhar NV. Pain relief by Dexamethasone as an adjuvant to local anaesthetics in supraclavicular brachial plexus block. Journal of Anaesthesiology Clinical Pharmacology. 2009; vol.25 (3) : 285288.

6. Lee JH, Cho SH, Kim SH, Chae WS, Jin HC, Lee JS, Kim YI . Ropivacaine for ultrasound-guided interscalene block: 5 $\mathrm{mL}$ provides similar analgesia but less phrenic nerve paralysis than 10 mL. Canadian Journal of Anesthesia. 2011; vol.58 (11):1001-6.

7. Attardi B, Takimoto K, Gealy R, Severns C, Levitan ES. Glucocorticoid induced upregulation of a pituitary $\mathrm{K}+$ channel mRNA in vitro and in vivo. Receptors Channels 1993; 1: 287-93

8. Kopacz DJ, Lacouture PG, Wu D, Nandy P, Swanton R, Landau C. The dose response and effects of Dexamethasone on Bupivacaine microcapsules for intercostal blockade (T9 to T11) in healthy volunteers. Anesthasia Analg. 2003; vol.96: 576-82.

9. Casati A, Fanelli G, Aldegheri G, Berti $\mathrm{M}$, Colnaghi E, et.al. Interscalene brachial plexus anaesthesia with $0.5 \%$, $0.75 \%$ or $1 \%$ Ropivacaine: a double-blind comparison with $2 \%$ mepivacaine. British Journal of Anaesth. 9 June 1999; vol.83: 872-5.

10. Shrestha BR, Maharjan SK, Tabedar S. Supraclavicular brachial plexusblock with and without dexamethasone - a comparative study. Kathmandu University medical journal. July 2003 ; vol. 1 (3): 158-160.

11. Madison SJ, Humsi J, Loland VJ, Suresh PJ, Sandhu NS, Bishop MJ, Donohue MC, Nie D, Ferguson EJ, Morgan AC, Ilfeld BM. Ultrasound-guided root/trunk (interscalene) block for hand and forearm anesthesia. Regional anesthesia and pain medicine 2013; vol.38 (3);226-32.

12. Desmet M, Braems H, Reynvoet $M$, Plasschaert S, Cauwelaert VJ, et.al. I.V. and perineural dexamethasone are equivalent in increasing the analgesic duration of a single-shot interscalene block with ropivacaine for shoulder surgery: a prospective, randomized, placebocontrolled study. British Journal of Anaesthesia. 15 April 2013; vol.111 (3): 445-52.

13. Stan T, Goodman EJ, Bravo- Fernandez C, Holbrook CR. Adding Methylprednisolone to local anaesthetic increases the duration of axillary block. Reg Anaesthesia Pain med 2004;29(4):380

14. Selander D. Catheter technique in axillary plexus block: presentation of a new method. Acta Anaesthesiologica Scandinavica 1977;21(4):324-9.

15. Johansson A, Hao J, SjolundB local corticosteroid application blocks transmission in normal nociceptive C- 


\section{JMSCR Vol||05||Issue||12||Page 31765-31771||December}

fibres. Acta anaesthesiolscand 1990;34:335-8.

16. Devor MD, Gorvin-Lippmann R, Raber P. Corticosteroids suppress ectopic neural dischargeoriginating in experimental neuromas. Pain 1985;22:127-37

17. Dräger C, Benziger D, Gao F, Berde CB. Prolonged intercostals nerve blockade in sheep using controlled-release of bupivacaine and dexamethasone from polymer microspheres.

18. Anesthesiology 1998;89:969-79.

19. Ahlgren SC, Wang JF, Levine JD. C-fiber mechanical stimulus-response functions are different in inflammatory versus neuropathic hyperalgesia in the rat. Neuroscience 1997;76:285-90.

20. Attardi B, Takimoto K, Gealy R et.al: Glucocorticoid induced upregulation of a pituitary $\mathrm{K}+$ channel mRNA in vitro and in vivo. Receptors channels 1: 287-93; 1993. 